\title{
Could Fast Response Curtail New Congo Ebola Virus Outbreak?
}

\author{
Philips Akinwole* \\ Biology Department, Dordt College, USA \\ *Corresponding author: Philips Akinwole, Biology Department, Dordt College, Sioux Center, USA
}

Submission: 眥: May 25, 2018 ; Published: 些June 11, 2018

\section{Opinion}

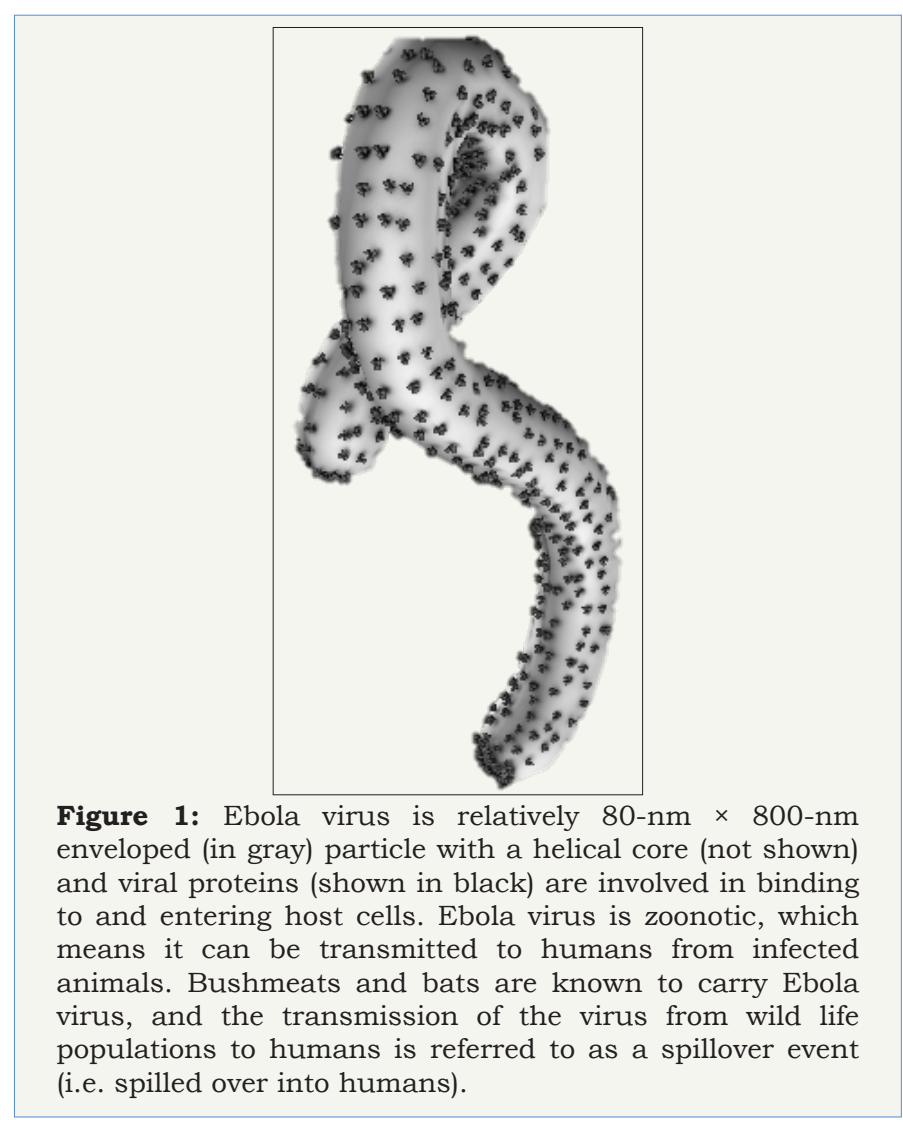

The 2013-2016 West Africa Ebola virus outbreaks was the first anywhere in the world to reach epidemic proportions - causing approximately 28,616 suspected cases and 11,310 reported deaths. The first cases of the deadly diseases were reported in Guinea in December 2013 and later spread to neighboring Liberia and Sierra Leone, with minor outbreaks in Nigeria and Mail and cases also being exported to Europe and the USA. WHO was widely criticized for its delay in taking actions to address the epidemic. Expected early alert is meant to mobilize foreign aids and actions. On August 8, 2014, WHO officially declared the outbreak a public health emergency of international concern. This declaration triggered a surge in outside help, for instance, U.S. President Barack Obama ordered up to 3,000 troops to Liberia and promised medical resources and the constructions of as many as 17 Ebola treatment centers in the region, with about 1,700 treatment beds. Britain pledged $£ 20$ million to build Ebola clinics, China sent a 59-person lab team and Cuba sent more than 400 health workers (Figure 1).

Ebola virus disease is caused by four of five viruses classified in the Filoviridae family, genus Ebolavirus with helical Five species of viruses have been established in the genus Ebolavirus: Zaire ebolavirus, Bundibugyo ebolavirus, Sudan ebolavirus, Taï Forest ebolavirus, and Reston ebolavirus. Of the four diseasecausing viruses (named for the region where each was originally identified), Zaire ebolavirus is the most dangerous and is the species responsible for the epidemic in West Africa and the latest outbreak in Congo. The name Ebolavirus is derived from the Ebola River in Zaire (now the Democratic Republic of the Congo-DRC), the location of the first outbreak in 1976.

The current, outbreak of the ebola virus in the DRC in central Africa has claimed more than two dozen lives and at least 58 others in DRC's northwest have shown Ebola symptoms since it was identified on May 8, 2018 in a rural setting in the North-western Equateur Province. However, cases were confirmed in Mbandaka, a city of nearly 1.2 million people, this is a concerning development.

Vaccine trials in its initial stages have been launched to stop the ebola outbreak. This time around, WHO, international agencies and the DRC government sprang into action and have begun administering experimental vaccine to hundreds of people deemed to be at risk, hoping to quickly extinguish the outbreak. WHO has sent 7,540 experimental vaccines made by pharmaceutical firm Merck to DRC so far with plans to send another 8,000 doses in the next few days. The experimental vaccine was successful in a clinical trial in Guinea at the tail end of the last West Africa epidemic in 2015 and probably contributed to controlling the outbreak of Ebola virus disease in Guinea. Henao Restrepo et al. [1] in their ring vaccination cluster-randomised trial in Guinea in 2015 to assess the efficacy of a single intramuscular dose of the rVSV-ZEBOV 
vaccine documented that the rVSV-ZEBOV vaccine was effective in protecting against Ebola virus infection.

The ebola vaccine genetically engineered to display ebola surface proteins has not been licensed for use by any country; however, it can be given as part of a trial protocol under compassionate use regulation. As part of ebola control response, vaccinated people will be followed for 84 days to assess whether any of the vaccinated group will develop ebola disease and to evaluate possible side effects.

Since ebola has a 21-day incubation period, as soon as cases are confirmed vaccination can offer protection to the circle of people who were in contact with those infected, but also to a second ring of people who've had contact with the first group, and thus, potentially break the disease's transmission chain. That's why vaccination is really important in this Ebola response if we want to curtail the current outbreak.

WHO Deputy Director-General for Emergency Preparedness and Response Peter Salama is optimistic about the current development, "Today marks a turning point in how we deal with \#Ebola - we are moving from a strategy of containment to one of offering communities protection and care" He said on Twitter.

\section{References}

1. Henao Restrepo, Camacho AM, Longini A, Watson IM, Edmunds $\mathrm{CH}$ et al. (2017) Efficacy and effectiveness of an rVSV-vectored vaccine in preventing Ebola virus disease: final results from the Guinea ring vaccination, open-label, cluster-randomised trial (Ebola Ça Suffit!). The Lancet 389(10068): 505-518.
Creative Commons Attribution 4.0 International License

For possible submissions Click Here

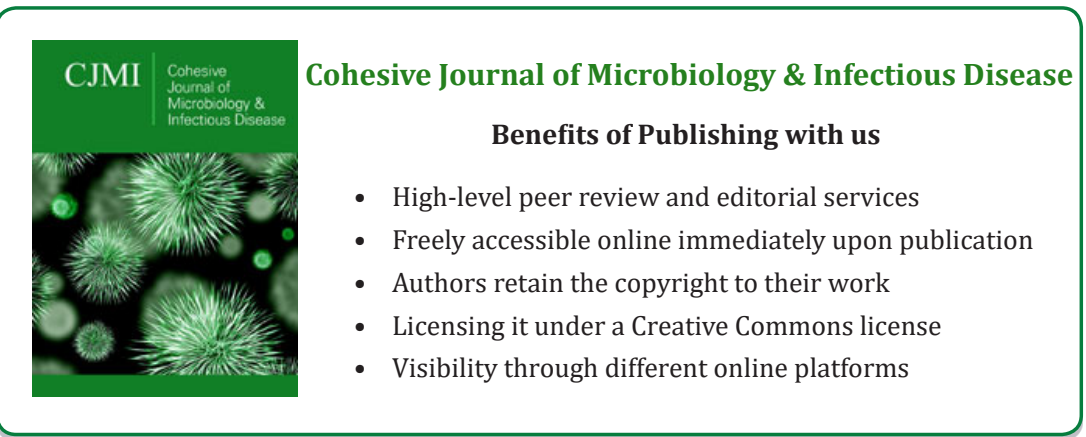

